\title{
OS EFEITOS DA GLOBALIZAÇÃO NAS ECONOMIAS BRASILEIRA E CHINESA: A IMPORTÂNCIA DAS POLIITICAS INTERNAS
}

Caroline Giusti Araújo ${ }^{1}$ Antônio Carlos Diegues ${ }^{2}$

Resumo: Este trabalho tem como objetivo analisar os efeitos do processo de globalização nas economias brasileira e chinesa. A tese central é que a globalização e seus desdobramentos representaram riscos, mas também oportunidades aos países em desenvolvimento que poderiam ser aproveitadas por meio da condução das políticas internas. Ademais, utilizam-se indicadores construídos a partir do valor adicionado doméstico nas exportações e o índice de complexidade econômica. De modo geral, notou-se que o aumento da participação nas cadeias globais de valor não implicou transformação estrutural para as duas economias. Isto é, enquanto a economia chinesa busca superar o path dependence e utilizar a globalização como uma "janela de oportunidade", via diversificação produtiva, o Brasil caminha para outros rumos.

Palavras-chaves: Globalização. Brasil. China.

\section{THE EFFECTS OF GLOBALIZATION IN THE BRAZILIAN AND CHINESE ECONOMIES: THE IMPORTANCE OF INTERNAL POLICIES}

Abstract: This research aims to analyze the effects of the globalization in the Brazilian and Chinese economies. The central thesis is that globalization and its consequences have risks, but also opportunities for developing countries that could be exploited by the internal policies. Besides, indicators are constructed from domestic value added in exports and the economic complexity index. In general the increase in participation in value chains did not imply structural transformation for both economies as the Chinese economy has sought to overcome path dependence and use globalization as a "window of opportunity", through the diversification of the productive structure, and the Brazilian is going for another way.

Keywords: Globalization. Brazil. China.

\section{LOS EFECTOS DE LA GLOBALIZACIÓN EN LAS ECONOMÍAS BRASILEÑAS Y CHINAS: LA IMPORTANCIA DE LAS POLÍTICAS INTERNAS}

Resumen: Este artículo tiene como objetivo analizar los efectos del proceso de globalización en las economías brasileña y china. La tesis central es que la globalización y sus consecuencias representaban riesgos, pero también oportunidades para los países en desarrollo que podrían explotarse a través de la conducción de políticas internas. Además, son usados indicadores laborados a partir del valor agregado interno en las exportaciones y el índice de complejidad económica. En general, aumentar la participación en las cadenas de valor mundiales no ha resultado en una transformación estructural para ambas economías, esto es, mientras que la economía china busca superar la dependencia del camino y utilizar la globalización como una "ventana de oportunidad", a través de la diversificación productiva, Brasil se dirige a otras direcciones.

Palabras clave: Globalización. Brasil. China.

\footnotetext{
1 Unicamp, Departamento de Política Científica e Tecnológica, Campinas, Brasil carolgiustiaraujo@gmail.com, https://orcid.org/0000-0002-7712-1092

2 Unicamp, Núcleo de Economia Industrial e da Tecnologia, Instituto de Economia, Campinas, Brasil, diegues@unicamp.br, https://orcid.org/0000-0002-4124-666X
} 


\section{Introdução}

O objetivo deste trabalho é analisar os efeitos do processo de globalização nas economias brasileira e chinesa. A tese central deste artigo argumenta que a globalização e seus desdobramentos, como a fragmentação da estrutura produtiva, representou riscos, mas também oportunidades aos países em desenvolvimento que poderiam ser aproveitadas por meio da condução de políticas internas.

No que diz respeito ao processo de globalização, Ortuso (2014) avalia a liberalização do comércio tendeu a tornar o planeta um espaço homogêneo para as vendas e facilitar a fabricação dos produtos finais em diferentes países. A liberalização dos fluxos de capitais facilitou o deslocamento da produção via investimento direto e circulação de capital de curto prazo. No entanto, essas não foram capazes de promover a modernização tecnológica e ganhos de produtividade para todos. Isto é, países em desenvolvimento tiveram maiores entraves para se beneficiarem.

Nessa perspectiva, observa-se na economia brasileira que os anos 1990 se caracterizaram pela combinação de abertura comercial, câmbio sobrevalorizado e taxa de juros elevadas sem uma correspondente política industrial propriamente articulada. Isto resultou em um processo de significativo aumento no coeficiente de penetração de importação na economia, com destaque para setores intensivos em tecnologia e capital. A indústria brasileira ampliou sua integração como importadora nas cadeias globais de valor. Além disso, a literatura aponta para uma especialização da atividade produtiva em bens intensivos em recursos naturais.

No caso chinês, por outro lado, os anos 1980 e 1990 representaram anos de condução estratégica das políticas domésticas que sustentaram a maior participação nos fluxos de comércio internacional do país a partir dos anos 2000, com a entrada da China na Organização Mundial do Comércio. Nesse sentido, observa-se que a partir de meados dos anos 2000 o país intensificou o desenvolvimento de setores com maior dinamismo industrial. Isto é, através da política industrial focada em setores chaves, a China constituiu um tecido industrial internacionalmente competitivo, reposicionando-se na perspectiva das cadeias globais de valor.

Além desta breve introdução, este artigo está estruturado nas seguintes seções: ii) o fenômeno da globalização; iii) as divergências do acoplamento periférico: o caso brasileiro e chinês; iv) o comportamento do Brasil e da China nos 
indicadores de valor adicionado doméstico nas exportações e da complexidade econômica e v) considerações finais.

\section{O fenômeno da globalização}

Na segunda metade do século XX, a expansão mundial do capitalismo sob a hegemonia americana mudou a divisão internacional do trabalho e a relação centroperiferia proposta pela hegemonia inglesa. A hegemonia dos Estados Unidos foi exercida mediante a expansão da grande corporação americana e seus bancos. Sabe-se que no imediato pós-guerra, sob a égide de Bretton Woods, o poder do dólar conversível sustentou três processos simultâneos: 1) o déficit na conta de capitais americana que garantiu o abastecimento da liquidez requerida para 0 crescimento do comércio mundial; 2) a reconstrução dos sistemas industriais da Europa e do Japão; e 3) a industrialização de muitos países da periferia, impulsionada pelo investimento produtivo direto em conjugação com políticas de desenvolvimento nacional.

Neste período os Estados Unidos permitiram o nacionalismo econômico asiático, aceitando as estratégias de crescimento acelerado que contemplavam políticas industriais protecionistas e fortes incentivos às exportações. Neste contexto, o Brasil também utilizou políticas nacionais de industrialização que, no âmbito doméstico, promoveram a "internacionalização" da economia, ou seja, a repartição de tarefas entre as corporações multinacionais, as empresas estatais e os empreendimentos privados nacionais. Trata-se de um período em que foram criados mecanismos e instituições visando a estabilidade das relações internacionais de forma que políticas de inspiração keynesianas foram aplicadas, estimulando o crescimento da renda, do emprego e a redução do gap de produtividade dos países em relação a economia líder. (SARTI E HIRTUKA, 2010)

Essa etapa conhecida como a era dourada do capitalismo terminou na crise do dólar de 1971 e na decretação unilateral da inconversibilidade da moeda americana. A regeneração do papel do dólar como standard universal foi efetivada mediante uma elevação sem precedentes das taxas de juros, em 1979. De acordo com Belluzzo (2014) a reabilitação do padrão-dólar deu novo impulso à redistribuição da capacidade produtiva na economia mundial e estimulou o movimento de fusões e aquisições dos anos 80 ampliando os desequilíbrios nos balanços de pagamentos entre os EUA, a Ásia e a Europa, bem como o avanço da 
chamada globalização financeira, isto é, o acordo distributivo da "era de ouro" havia se esgotado.

Segundo Belluzzo (2014) o "modelo asiático" em sua forma atual tem uma relação simbiótica com as transformações financeiras e organizacionais que deram origem às novas formas de concorrência entre as empresas dominantes da tríade desenvolvida - Estados Unidos, Europa e Japão. Isto é, a nova concorrência respondeu às políticas dos anos 80 de forma que a grande empresa buscasse reconfigurar o ambiente internacional. Assim, para além de reafirmar a importância crescente do comércio intra-firmas, houve um processo de "global sourcing", internacionalizando cadeias de fornecedores.

Logo, notou-se a origem a fenômenos correlacionados e aparentemente contraditórios: 1) uma nova etapa de "centralização" da propriedade e do controle dos blocos de capital; 2) a "terceirização" das funções não-essenciais à operação do core business, que aprofundou a divisão social do trabalho. Ademais, esse novo paradigma acentuou a importância das vantagens da propriedade das competências core nos processos produtivos, em que se destacam: a) processos cumulativos de aprendizado (learning by doing na produção flexível); b) economias de escala dinâmicas; c) emergência das tecnologias da informação e comunicação que maximizaram a eficiência da gestão e controle ao longo das cadeias de agregação de valor; d) novas economias de aglomeração; e) economia derivada da cooperação tecnológica e do co-desenvolvimento de produtos e processos. (BELUZZO, 2014)

Esse cenário de transformações fez com que o mundo presenciasse um "cataclismo" na divisão internacional do trabalho. (BELUZZO, 2014) Isto é, o aumento da incerteza e da volatilidade associado ao desenvolvimento da tecnologia da informação e comunicação fizeram com que a busca pelo desenvolvimento de ativos intangíveis (relacionados a inovação tecnológica e também de técnicas de gestão, diferenciação de produto qualificação de mão-de-obra, patentes) recebesse atenção crescente das empresas transnacionais. (SARTI E HIRTUKA, 2010)

Nesse arcabouço, os países em desenvolvimento tiveram espaço para aumentar sua participação no produto industrial global. No entanto, esse movimento foi assimétrico entre os países produtiva e comercialmente. (SARTI e HIRATUKA, 2010) Os autores apresentam dados da UNIDO ${ }^{3}$ mostrando que o fenômeno de avanço dos países em desenvolvimento representou uma dinâmica virtuosa para a

\footnotetext{
3 United Nations Industrial Development Organization.
} 
Ásia à medida que essa conseguiu alavancar sua participação no total das exportações de 1980 a 2002, inclusive em setores de média e alta intensidade tecnológica.

A China percebeu a implicação das mudanças internacionais e buscou articular o máximo de competição (via globalização) e controle ${ }^{4}$ (principalmente através dos investimentos e empresas estatais). Com isso, Belluzzo (2014) avalia que os chineses entenderam que as políticas liberais recomendadas pelo Consenso de Washington ${ }^{5}$ não deveriam ser "copiadas" pelos países emergentes, ou seja, a adoção do modelo envolveria uma estratégia e planejamento para que o mesmo pudesse beneficiar o desenvolvimento local.

Por sua vez, o Brasil e a América Latina ficaram à margem do processo de reestruturação das cadeias globais de valor. Isto é, mesmo superado o problema da estabilização inflacionária, em 1994, não houve grande capacidade em promover diferenciação da estrutura industrial brasileira. $\mathrm{Na}$ maioria dos casos, o Brasil participa das cadeias globais na ponta final do processo produtivo. Além disso, Belluzzo (2014) destaca que nos últimos quarenta anos o país fez adições marginais à estrutura manufatureira. A modernização restringida implicou o aumento da importação de bens de capital e o abandono da indústria de equipamentos, fazendo com que a dependência das importações se tornasse estrutural.

Ortuso (2014) avalia que as cadeias globais de valor devem ser analisadas como um mundo em que poucas grandes empresas dominam o mercado global e impõem barreiras à entrada. Assim, aumentar o tamanho da empresa e seu espaço no mercado não é uma questão de escolha individual, isto é, quando as escalas de produção eram menores, o espaço de uma região ou de um país era suficiente. $\mathrm{Na}$ medida em que as escalas aumentavam foi preciso expandir o volume de vendas via exportações. Na sequência, a estratégia foi abrir filiais em países estrangeiros. Por fim, a grande empresa definitivamente tornou-se transnacional, isto é, a grande

\footnotetext{
${ }^{4}$ Nessa perspectiva, Milaré (2011) propõe como construto analítico do desenvolvimentismo industrial chinês a partir da tríade "autonomia -planejamento-controle". O autor mostra que por meio da tríade liderada pelo Estado chinês foi possível o país aproveitar o contexto geopolítico de desenvolvimento a convite para dinamizar sua pauta exportadora e estrutura doméstica.

5 O Consenso de Washington representava dez medidas a serem adotadas pelos países latinoamericanos com pronto apoio de Washington: i) déficits orçamentários; ii) gastos públicos direcionados a áreas sensíveis; iii) reforma tributária; iv) liberalização financeira com taxa de juros determinada pelo mercado; v) taxa de câmbio unificada a nível competitivo; vi) restrições comerciais quantitativas a serem substituídas por tarifas; vii) abolição de barreiras ao investimento externo; viii) privatização de empresas estatais; xix) abolição de regulamentações que impeçam a competição; $x$ ) garantia do direito de propriedade, especialmente para o setor informal de acordo com a listagem apresentada por CORRÊA (2007, p.34 apud WILLIANSOM, 2004, p.284)
} 
empresa chandleriana foi desverticalizada e as barreiras à entrada passaram a envolver além de gastos com P\&D, a capacidade de absorver (COEHN E LEVINTHAL, 1990) o conhecimento disponível.

Na perspectiva da formação das cadeias globais de valor, Gereffi et al (2005) argumentam que tanto a globalização da produção quanto da comercialização de bens e serviços geraram um processo de desintegralização vertical das cadeias produtivas construídas na esfera nacional. As empresas passaram a transferir as atividades não fundamentais para países em desenvolvimento, que apresentassem vantagens comparativas em termos de custos de produção, e se concentrarem nas atividades core, com maior valor agregado, reduzindo custos sem perder o domínio das áreas mais nobres.

Beraldo (2017) destaca que a importância da reorganização da estrutura produtiva ao redor das redes globais se dá à medida que esse processo oferece uma oportunidade de modificação na divisão internacional do trabalho alterando, assim, a geopolítica de diversas regiões. Neste sentido, "a história, as instituições, os contextos geográficos e sociais, a evolução das regras do jogo e o path dependence são importantes" (GEREFFI, et. al. 2005, p. 82). Isto é, a reconfiguração do comércio internacional representa apenas um vetor em uma matriz complexa de variáveis -econômicas, políticas, institucionais, regulatórias e organizacionais - que influenciam o reposicionamento internacional. Como destaca Lall (2002):

Todavia, não reduz a necessidade de capacitação e instituições locais; muito pelo contrário, a força do sistema local de aprendizagem torna-se cada vez mais importante para atrair e "enraizar" os recursos móveis que se acham disponíveis no exterior. Pelo simples fato de o capital e as tecnologias estarem mais acessíveis (e mais livres para se movimentar), os países têm que oferecer qualificações, potencialidades, redes de abastecimento, instituições e infraestrutura melhores para atrair recursos de alta qualidade. A simples abertura das economias para as forças do mercado global, sem aprimorar as qualificações e as potencialidades, pode servir para explorar a capacidade já existente, mas, a prazo mais longo, pode ser a receita da estagnação na base da escala tecnológica e de renda. (LALL, 2002, p.129).

Por fim, ressalvam-se as considerações feitas por Hiratuka e Sarti (2017) a respeito da profundidade das discussões sobre as políticas nacionais em um cenário de acirramento da competição global com o espraiamento da produção e a governança das etapas core das cadeias produtivas. Os autores avaliam que a concorrência internacional se acirrou a partir de 2007-2008 com a crise internacional reacendendo o debate sobre a retomada da capacidade de produção manufatureira 
e a necessidade de avanço da inovação em áreas estratégicas em diversos países. Assim, os desafios endógenos são colocados em um arcabouço internacional que agudiza os desafios industrial, científico e tecnológico. (p.205)

\section{As divergências no acoplamento global periférico: o caso brasileiro e chinês}

\section{A emergência da China}

Aglietta (2013) ao buscar entender o desenvolvimento chinês argumenta que os anos 1950 e suas reformas foram fatores necessários para o sucesso da abertura e que a concentração e acumulação de recursos, inclusive humano, para a emergência de inovações industriais, foram indispensáveis. Nesse sentido, analisa que o regime econômico e o sistema político tradicional chinês impunham obstáculos ao processo de industrialização que não seriam superados apenas pelo mercado.

A partir das reformas feitas em 1978 a política de preços agrícolas começou a ser reajustada e as States Owned Enterprise (SOEs) - empresas comandadas pelo Estado, pivô da articulação do desenvolvimento industrial chinês - começaram a sofrer concorrência de pequenas e médias empresas que surgiam na China, além das Townships Villages Enterprise (TVEs) e empresas estrangeiras situadas nas regiões costeiras - onde foram criadas as Zonas Econômicas Especiais (ZEEs). A situação das SOEs era preocupante e colocava o governo e o sistema bancário em risco. Com isso, foram fechados setores não lucrativos e não estratégicos e, as que foram mantidas, passaram a ocupar posições monopolísticas no mercado concentrando recursos materiais e financeiro, aumentando a produtividade industrial.

Aglietta (2013) avalia que a segunda onda de reformas na China foi concomitante ao processo de globalização, isto é, condições internacionais propicias para exportação, que aliviaram os impactos negativos da organização estrutural vigente até então. Assim, a estratégia industrializante chinesa passaria pelo ímpeto de fazer com que sua estrutura produtiva atendesse ao mercado externo. Por meio das exportações, o país conseguiria internalizar o dinamismo externo e, assim, modernizar sua indústria. Outras estratégias com mesmo intuito foram atração de Investimento Direto Externo (IDE), que além de trazer o capital externo produtivo, atraia know-how; o incentivo à cópia e à engenharia reversa; manutenção do câmbio artificialmente desvalorizado; financiamento estatal para novos empreendimentos a taxas de juros menores e altas taxas de investimento (MILARE, 2011). 
Medeiros (2013) destaca que a base essencial do dinamismo exportador chinês, ao longo das duas últimas décadas, foi a sua integração por meio do processamento de exportações na cadeia produtiva lideradas pelos produtores da indústria de tecnologia da informação e na cadeia liderada pelos consumidores da indústria leve de consumo. A codificação e a modularização de processos produtivos permitiram o deslocamento para a China de atividades de montagem de processos produtivos com elevada importação de componentes e produtos intermediários. Isto é, pela via do deslocamento dos fluxos de IDE e condições estruturais propícias o país pode se inserir internacionalmente.

Porém, analisa-se que as estratégias de internacionalização foram conduzidas pelo Estado a fim de viabilizar a presença do mercado sem a perda da autonomia nacional ${ }^{6}$. A entrada do capital externo na forma do IDE, por exemplo, seguiu a lógica de planejamento estatal. Cunha e Xavier (2010) avaliam que 90\% do IDE que entrou na China foi destinado à modernização do capital e ampliação da capacidade produtiva existente.

Assim, percebe-se que o país promoveu um ambiente macroeconômico e institucional diferenciado de forma que a abertura econômica não se restringiu apenas a permitir a livre movimentação de capitais. Além disso, a política cambial de desvalorização da moeda local se tornou parte da política macroeconômica e industrial em 1984 -principalmente durante o desenvolvimento do parque industrial e foi intensificada com o estabelecimento de um regime dual de câmbio - o oficial (administrado) e o mercado de swaps, que era restrito as empresas instaladas nas ZEEs e tradings Estatais. (MILARÉ, 2011; ARAÚJO, BRANDÃO E DIEGUES, 2018)

A partir de meados dos anos 2000 a China intensificou o desenvolvimento de setores com maior dinamismo industrial, articulando-se ao cenário internacional por meio da estratégia "going global". Masiero e Coelho (2014) analisam que através da política industrial focada no processo de inovação em setores chaves, principalmente, químico, eletrônico e metal-mecânico, o país constituiu um tecido industrial internacionalmente competitivo, atraindo empresas internacionais para produção local e também para se articularem às empresas nacionais fazendo que

\footnotetext{
${ }^{6}$ Essa atuação participativa do Estado chinês no comando do processo de industrialização e desenvolvimento econômico do país pode ser entendida pela ótica de que a convergência de renda entre os países industrializados e os não-industrializados não se trata de um resultado natural da dinâmica econômica.
} 
tecnologias próprias fossem produzidas a partir da China. Para os autores, esse movimento tem acirrado a concorrência com players tradicionais, definindo uma "nova geografia econômica" e gerando, via participação Estatal, linkages, leverage, learning e indigenous innovation. (MASIERO E COELHO, 2014)

Na perspectiva das cadeias globais de valor, avalia-se que a China ainda está inserida como produtora de produtos com menor valor adicionado em relação aos países desenvolvidos, que segundo Cintra e Pinto (2015) ainda estão no topo da hierarquia das cadeias de produção. No entanto, entende-se que há um movimento por parte do Estado chinês em fomentar o desenvolvimento da inovação que podem ser avaliados na aprovação do programa de inovação autóctone (indigenous innovation) destacado tanto em Cintra e Pinto (2015) quanto em Cassiolato e Podcameni (2015).

Além disso, destaca-se o Plano "Made in China 2025" (2017) que visa endogeneizar a P\&D, substituir a dependência tecnológica internacional e capturar market share global. Wang (2016) destaca que o plano é pautado por oito políticas: fabricação em rede digital inteligente; melhorar a capacidade de design de produto; melhorar o sistema de inovação de tecnologia de produção; melhorar a qualidade do produto; implementação de manufatura verde; desenvolvimento de grupos empresariais globalmente competitivos e serviços de fabricação moderna. Liu (2018) avalia que o objetivo do plano é criar marcas chinesas, fomentar tecnologias cuttingedge, pesquisar novos materiais e produzir partes e componentes chaves dos produtos, enfatizando a indústria 4.0

\section{Um breve retrospecto do desenvolvimento industrial brasileiro}

$\mathrm{Na}$ perspectiva da globalização, os países latinos, de forma genérica, renegociavam dívidas, buscaram solucionar questões inflacionárias, introduzir as reformas liberalizantes e flexibilizarem as relações capital/trabalho, como propunha o Consenso de Washington. Para tal, utilizavam-se de juros elevados, controle da expansão dos meios de pagamento, valorização do câmbio, corte de gastos públicos. Com isso, os juros elevados atraiam o capital externo e o câmbio valorizado estimulava as importações, mantendo-se como âncora dos preços internos, como foi no Brasil durante a implementação do real.

Palma (2004) ao analisar a América Latina discute que a estrutura política e institucional da região sucede concentrando os benefícios do desenvolvimento, 
antes e depois do processo de substituição de importações, para uma pequena parcela da população. Para o autor, de forma geral, o estreitamento de laços entre a América Latina e o resto do mundo nos anos 1990 consolidou sua posição exportadora de recursos naturais. O autor discute a região deveria se atentar: i) a manufatura é o melhor motor do crescimento; ii) a manufatura é o meio para alcançar a renda média; iii) commodities não promovem um setor exportador dinâmico; iv) inflação é resultado de gargalos estruturais e v) apenas políticas governamentais discricionárias podem resolver esses problemas.

No que diz respeito a economia brasileira, os anos 1990 foi um período no qual as decisões de políticas econômicas repercutiram direta e indiretamente sobre a estrutura produtiva industrial. A combinação de abertura comercial, câmbio sobrevalorizado e taxa de juros elevadas sem uma correspondente política industrial articulada e coordenada engendrou um processo de aumento do coeficiente de penetração de importação na economia. (CARVALHO, 2007)

Neste sentido, observou-se um movimento de aumento contínuo e generalizado das importações no Brasil, principalmente no que diz respeito a bens intermediários. Isto, por sua vez, refletiu em um processo de substituição de fornecedores internos por externos. Segundo Morceiro et al (2014) a parcela dos insumos importados apresentou aumento generalizado no período entre 2003 e 2008, em que aproximadamente $60 \%$ de insumos comercializáveis utilizados na produção são importados. Com isso, a indústria vem perdendo seu peso na contribuição para o crescimento do PIB e na geração de emprego. Esta conjuntura, em que as lacunas da matriz industrial são preenchidas crescentemente por insumos importados, resulta no enfraquecimento dos elos produtivos.

Sarti e Laplane (2002) destacaram que embora o aumento da participação das importações na atividade industrial brasileira tenha permitido uma elevação da eficiência e de ganhos significativos na produtividade da indústria doméstica, não se traduziu em correspondente aumento nas exportações. Com isso, a estrutura produtiva brasileira tem se voltado para o abastecimento do mercado interno.

No período 2000-2005 a estrutura produtiva brasileira teve seu desenvolvimento caracterizado por um período de stop and go, isto é, em 2001 a crise energética freou a expansão da indústria, em 2003 e 2005 foi a política macroeconômica restritiva. Mas, ainda assim, houve expansão da participação industrial brasileira na indústria global no período, que, no entanto, não representou 
um desempenho suficiente para evitar perda de participação em relação aos países asiáticos. Além disso, essa perda também foi qualitativa, isto é, de produtos de maior intensidade tecnológica para as commodities agrícolas e minerais (SARTI E HIRATUKA, 2010). Para os autores, a indústria brasileira deixou de ser o vetor dinâmico do crescimento econômico no período analisado.

Sarti e Hiratuka (2017) analisam que o coeficiente de penetração das importações na indústria brasileira cresceu de 15,3\% para 22\% entre 2009 e 2015, assim como o coeficiente de insumos importados (de $22 \%$ para $28 \%$ no mesmo período) em contrapartida ao coeficiente de exportação, que apresentou queda entre 2003 a 2010 e permaneceu estagnado de 2010 a 2014, recuperando-se apenas a partir de 2015 em contexto de agravamento da recessão mundial e desvalorização cambial.

Diegues e Rossi (2016) avaliaram que entre 2000 e 2010 surgiu um novo padrão de organização e acumulação na esfera industrial brasileira. Esse novo padrão deu origem ao que os autores denominaram de Doença Brasileira, que representa um movimento de reconfiguração estrutural da indústria que se direciona à especialização regressiva e à desindustrialização em paralelo a estratégias que garantem a acumulação do capital industrial. A indústria brasileira passou a reduzir gradativamente o conteúdo local na produção ampliando sua integração como importadora nas cadeias globais de valor concomitante a elevação da massa de lucro do setor industrial (entre 2000 e 2010) em empresas com 30 ou mais ocupados. Assim, os autores identificaram uma nova forma de acumulação de capital que permite as empresas não se prenderem a esfera da produção. Dessa forma, contrariando ao esperado em um processo de desenvolvimento industrial, a apreciação cambial levou a um aumento da rentabilidade e lucratividade na indústria no período de 2000 a 2010.

Além disso, Bresser-Pereira e Marconi (2010) avaliaram que há sinais da ocorrência da doença holandesa na economia brasileira, isto é, de um processo em que apreciação cambial resulta na valorização dos preços das commodities e dos recursos naturais, levando a especialização da atividade produtiva e interrompendo o processo de industrialização.

No entanto, destaca-se que os meandros da literatura a respeito da desindustrialização brasileira não é objeto deste artigo, intenta-se apenas ressaltar, como faz Sarti e Hirtuka (2017), que diferente da China e de alguns países asiáticos, 
o Brasil não logrou uma inserção virtuosa nos fluxos de investimento, produção e comércio exterior nas últimas três décadas. Isto é, internacionalização produtiva tem levado a desnacionalização da base produtiva, reforçando "um padrão de inserção comercial assimétrico e dependente" (p.33).

Assim, os efeitos das políticas macroeconômicas brasileira nas últimas décadas e a nova configuração global da produção têm produzido impactos significativos sobre a estrutura industrial local. Nessa perspectiva, o país encontra dificuldades para se inserir competitivamente no cenário internacional da produção, aumentando a distância em relação às economias desenvolvidas e emergentes que têm conseguido se inserir de forma mais virtuosa neste processo, como a China.

\section{O comportamento do Brasil e da China nos indicadores de valor adicionado doméstico nas exportações e da complexidade econômica}

\section{Cadeias globais de valor: o caso brasileiro e chinês de 1995 a 2011}

O processo de globalização proporcionou uma "janela de oportunidade" aos países atrasados no desenvolvimento industrial através do espraiamento das cadeias produtivas. Taglioni e Winkler (2014) avaliam que a participação nas cadeias globais representa uma condição necessária ainda que não suficiente enfatizando o arcabouço doméstico - para o desenvolvimento industrial das nações. Com isso, busca-se a luz das transformações industriais discutidas avaliar a qualidade da inserção internacional brasileira e chinesa nas cadeias globais de valor e a complexidade econômica dos espaço-produto dos países.

É possível caracterizar a inserção internacional dos países pela via da adição de valor doméstico e estrangeiro nas exportações, dados disponibilizados pela base Tiva-OCDE7 ${ }^{7}$. Dessa forma, apresenta-se no Gráfico 10 indicador de participação ${ }^{8}$ nas cadeias globais de valor para a economia brasileira, norte-americana, mundial e chinesa para anos selecionados entre 1995 e 2011.

\footnotetext{
7 A "Trade in Value Added" TiVA database é parte da base derivada da versão 2016 do banco de dados de insumo-produto entre países da OCDE, calculada para 64 economias e 34 indústrias em milhões de dólares. Destaca-se que há uma versão recente da base de dados (2018) que não foi utilizada por disponibilizar dados a partir de 2005, prejudicando a análise de um contexto mais abrangente da globalização, dado que a versão de 2016 apresenta dados de 1995 até 2011.

${ }^{8} \mathrm{~A}$ participação nas cadeias globais de valor é calculada pela soma da participação para frente - que mensura a parcela de insumos produzidos em um país contidos na exportação - e da participação para trás - que mensura a importância de fornecedores estrangeiros para cada unidade exportada.
} 
Gráfico 1- Participação para frente, para trás e total do Brasil, China, Mundo e EUA nas cadeias de valor de $1995-2011$

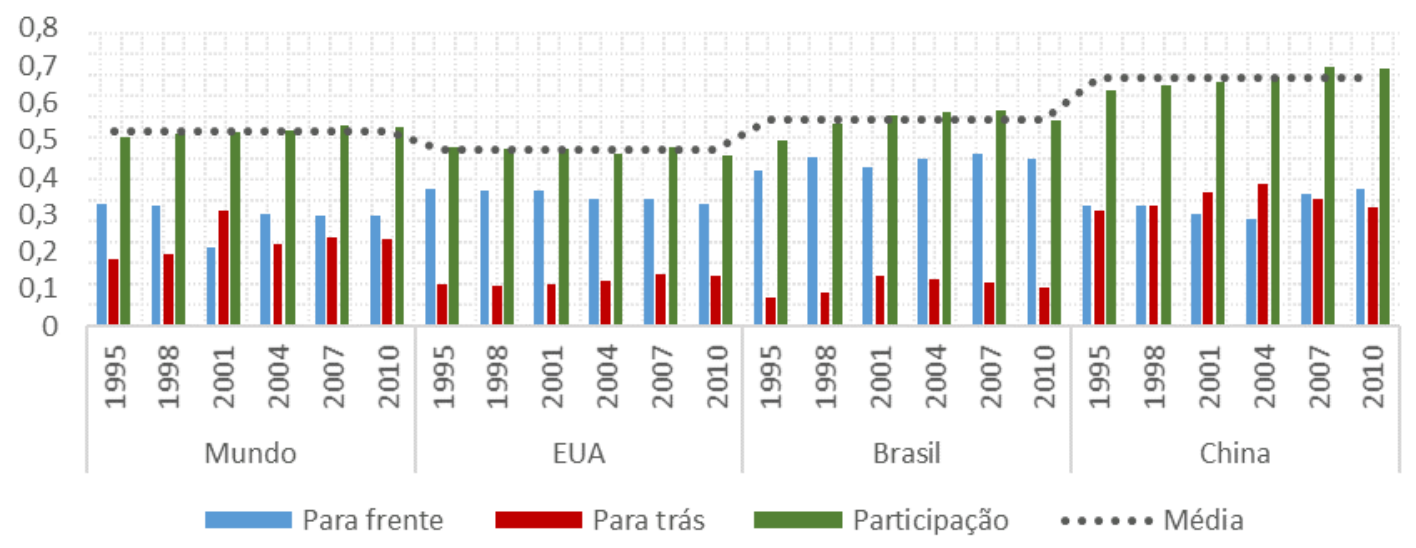

Fonte: Elaboração própria a partir de dados da base TiVA

Nota-se no Gráfico 1 que na média dos anos analisados a participação chinesa é maior que todas as demais economias avaliadas, inclusive a mundial. $\mathrm{Na}$ perspectiva comparativa, percebe-se que a economia brasileira apresenta 0 indicador para frente maior. No entanto, qualitativamente seu dinamismo está essencialmente associado ao desempenho do setor intensivo em recursos naturais, com menor dinamismo tecnológico. Esse padrão de inserção foi identificado por Hermida (2016) ao avaliar que a construção do indicador de participação nas cadeias propicia que países especializados em recursos naturais e produtos primários apresentem maior participação para frente comparativamente a países intensivos em serviços ou manufaturas de alta tecnologia.

No entanto, faz-se uma ressalva que o Brasil tem elevado sua participação para trás, aumentando sua integração internacional principalmente com relação ao setor intensivo em escala. A economia chinesa, por sua vez, tem elevado sua participação para frente em setores diferenciados. Com isso, pode-se notar que as economias estão se movendo no processo de integração internacional pela ótica da participação nas cadeias de valor. No entanto, entende-se que o dinamismo tecnológico avaliado nesse reposicionamento desfavorecerá a economia brasileira no longo prazo à medida que reforça setores que não promovem os maiores espraiamentos tecnológico, de emprego e renda. 
$\mathrm{Na}$ perspectiva comparada, apresenta-se no Gráfico 2 a dispersão da participação nas cadeias globais de valor para o Brasil e a China entre os anos de 1995 a 2011 com os setores industriais categorizados por tipo de tecnologia ${ }^{9}$. Buscase, com isso, comparar a evolução qualitativa da inserção internacional das duas economias. Nota-se que em tecnologias como a intensiva em escala houve uma aproximação da participação enquanto tecnologias como a diferenciada e a intensiva em recursos naturais houve um distanciamento, com a China aumentando sua participação naquela e o Brasil nessa. Essa dispersão sinaliza diferentes especializações tecnológicas por partes dos países configurando um distanciamento qualitativo no processo de acoplamento internacional.

Gráfico 2- Dispersão da participação nas cadeias globais de valor para o Brasil e a China por tipo de tecnologia - 1995-2011

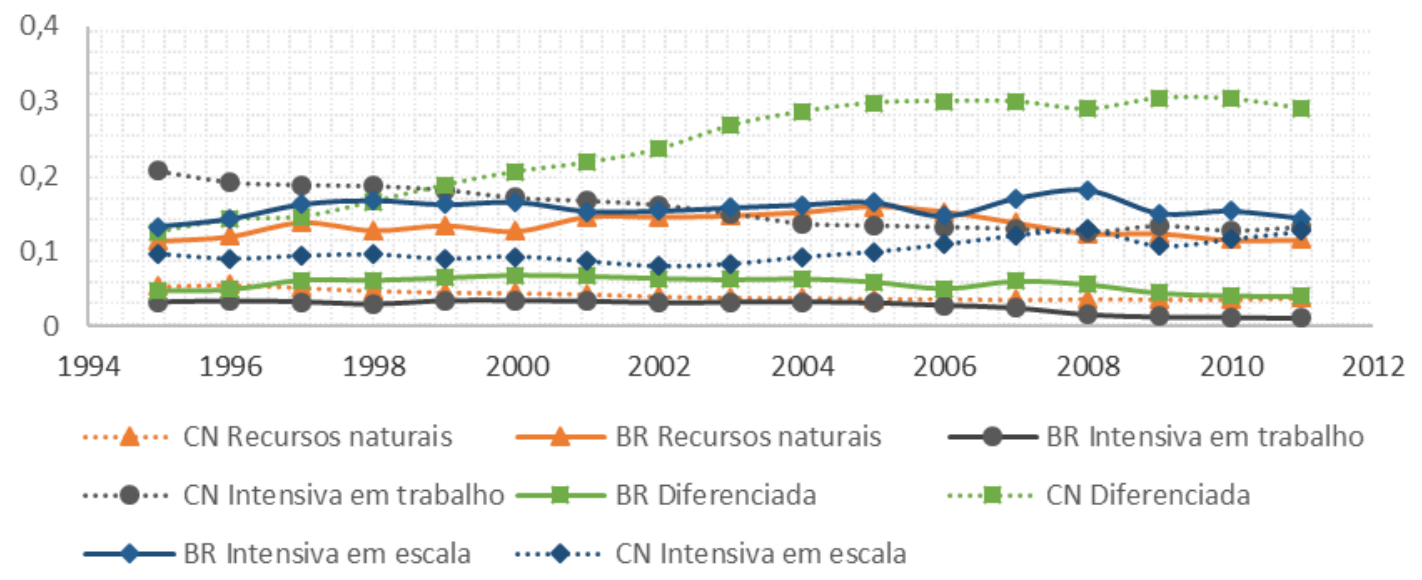

Fonte: Elaboração própria a partir de dados da base TiVA

Considerando, no entanto, a necessidade de avaliar melhor o distanciamento qualitativo brasileiro e chinês no comércio internacional, decompõe-se, ainda utilizando os dados da TiVA, o valor adicionado nas exportações em valor adicionado doméstico e estrangeiro para a agricultura e mineração, manufatura e o setor de serviços. Nota-se que tanto no caso brasileiro quanto chinês, o valor adicionado doméstico é maior em todos os setores que o valor adicionado estrangeiro, isto é, ambas ainda produzem maior percentual do que exportam nas fronteiras nacionais. Tal fato deve-se, possivelmente, ao tamanho das economias. No entanto, esse dado evidencia um movimento distinto para a economia brasileira e chinesa à medida que entre 2000 e 2011 o valor adicionado doméstico está

\footnotetext{
${ }^{9}$ Com relação à divisão por tipo de tecnologia, utilizou-se a taxonomia proposta pela OECD (1997), inspirada na taxonomia proposta por Pavitt (1984) em que se decompõe os setores industriais em intensivo em trabalho, escala, baseado em recursos naturais, ciência e diferenciado.
} 
reduzindo seu crescimento em benefício do valor adicionado estrangeiro na economia brasileira, inclusive no setor de manufatura. Em contrapartida, a China encontra-se fazendo o movimento oposto, com exceção do setor de serviços.

Por fim, apresenta-se na Tabela 1 os resultados dos índices market share ${ }^{10} \mathrm{e}$ vantagens comparativas reveladas ${ }^{11}$ utilizando o cálculo "tradicional" por meio das exportações brutas, representados por MS_t e VCR_t, e o cálculo por meio do "valor adicionado", expressos por MS_va e VCR_va. Koopman, Wang e Wei (2012) avaliam que a dupla contagem oferece distorção a definição da vantagem comparativa revelada proposta por Balassa (1965). Dessa forma, uma maneira de lidar com o problema seria avaliando o indicador através do valor agregado doméstico às exportações. Os dados estão expressos para os anos de 2001, 2004, 2007 e 2010 com os setores industrias agregados em tipo de tecnologia, conforme OCDE (1987).

Tabela 1- Índices market share e vantagem comparativa revelada tradicional e por valor adicionado para o Brasil e a China com os setores industriais categorizados por tipo de

\begin{tabular}{|c|c|c|c|c|c|c|c|c|c|c|c|}
\hline \multirow{2}{*}{$\begin{array}{l}\text { Tipo de } \\
\text { tecnologia }\end{array}$} & \multirow{2}{*}{ Indicador } & \multicolumn{2}{|c|}{1995} & \multicolumn{2}{|c|}{2000} & \multicolumn{2}{|c|}{2005} & \multicolumn{2}{|c|}{2010} & \multicolumn{2}{|c|}{$\begin{array}{l}\Delta \text { 2001- } \\
2010 \\
\end{array}$} \\
\hline & & $\mathrm{CN}$ & BR & $\mathrm{CN}$ & BR & $\mathrm{CN}$ & BR & CN & BR & $\mathrm{CN}$ & BR \\
\hline \multirow{4}{*}{$\begin{array}{l}\text { Baseado em } \\
\text { recursos } \\
\text { naturais }\end{array}$} & MS_t & 0,08 & 0,19 & 0,06 & 0,19 & 0,05 & 0,24 & 0,05 & 0,17 & $-0,41$ & $-0,10$ \\
\hline & MS_va & 0,08 & 0,19 & 0,07 & 0,19 & 0,06 & 0,23 & 0,05 & 0,17 & $-0,39$ & $-0,08$ \\
\hline & VCR_t & 0,97 & 2,26 & 0,82 & 2,42 & 0,61 & 2,76 & 0,54 & 1,92 & $-0,44$ & $-0,15$ \\
\hline & VCR_va & 0,96 & 2,29 & 0,88 & 2,50 & 0,70 & 2,90 & 0,58 & 2,10 & $-0,39$ & $-0,09$ \\
\hline \multirow{4}{*}{$\begin{array}{l}\text { Intensiva em } \\
\text { trabalho }\end{array}$} & MS_t & 0,27 & 0,08 & 0,24 & 0,07 & 0,19 & 0,07 & 0,17 & 0,03 & $-0,36$ & $-0,63$ \\
\hline & MS_va & 0,24 & 0,08 & 0,24 & 0,07 & 0,20 & 0,07 & 0,18 & 0,03 & $-0,25$ & $-0,64$ \\
\hline & VCR_t & 3,20 & 0,93 & 3,11 & 0,92 & 2,54 & 0,89 & 2,44 & 0,41 & $-0,24$ & $-0,56$ \\
\hline & VCR_va & 3,11 & 1,01 & 3,30 & 1,01 & 2,95 & 0,97 & 2,75 & 0,43 & $-0,11$ & $-0,57$ \\
\hline \multirow{4}{*}{ Diferenciada } & MS_t & 0,17 & 0,08 & 0,26 & 0,11 & 0,37 & 0,09 & 0,38 & 0,07 & 1,23 & $-0,21$ \\
\hline & MS_va & 0,10 & 0,08 & 0,14 & 0,10 & 0,23 & 0,08 & 0,28 & 0,06 & 1,92 & $-0,23$ \\
\hline & VCR_t & 0,90 & 0,45 & 1,29 & 0,54 & 2,06 & 0,51 & 2,22 & 0,39 & 1,46 & $-0,13$ \\
\hline & VCR_va & 0,56 & 0,47 & 0,80 & 0,56 & 1,52 & 0,56 & 1,98 & 0,44 & 2,55 & $-0,06$ \\
\hline \multirow{4}{*}{$\begin{array}{l}\text { Intensiva em } \\
\text { escala }\end{array}$} & MS_t & 0,14 & 0,25 & 0,13 & 0,27 & 0,13 & 0,25 & 0,16 & 0,24 & 0,15 & $-0,04$ \\
\hline & MS_va & 0,11 & 0,24 & 0,11 & 0,26 & 0,13 & 0,23 & 0,15 & 0,22 & 0,38 & $-0,07$ \\
\hline & VCR_t & 0,54 & 0,98 & 0,54 & 1,14 & 0,55 & 1,03 & 0,66 & 1,00 & 0,21 & 0,01 \\
\hline & VCR_va & 0,47 & 1,01 & 0,51 & 1,19 & 0,59 & 1,08 & 0,71 & 1,03 & 0,50 & 0,02 \\
\hline
\end{tabular}

\footnotetext{
$10 \mathrm{O}$ market share representa as exportações de um país em um setor em relação às exportações mundiais naquele mesmo setor.

11 O índice de vantagem comparativa revelada foi desenvolvido por Balassa (1965) e representa uma medida do padrão de especialização comercial dos países. Isto é, o índice avalia a especialização de um país em um determinado setor (percentual das exportações de um setor em relação à pauta exportadora total do país) e a compara com a especialização do mundo no mesmo setor (percentual das exportações do mundo em um determinado setor em relação às exportações totais do mundo) permitindo desta forma avaliar se um país possui vantagens comparativas naquele setor em relação ao mundo.
} 
Fonte: Elaboração própria a partir de dados da base TiVA

A Tabela 1 permite avaliar o grau de especialização comercial sem subestimar ou superestimar o indicador ao analisá-lo pela ótica do valor adicionado, excluindo a dupla contagem presente com o processo de aprofundamento da integração comercial internacional. Para isso, marcou-se em azul os ganhos das tecnologias em que a China apresenta vantagens comparativas pelas duas métricas e em verde o Brasil.

Nota-se que essencialmente o Brasil possui vantagens comparativas ligadas aos setores primários e aos setores industriais intensivos em recursos naturais. Já a China possui vantagens comparativas ligadas aos setores industriais intensivos em trabalho e diferenciados. É possível avaliar ainda que as estatísticas tradicionais superestimam as vantagens comparativas brasileiras nestes setores e as chinesas nos setores diferenciados. No entanto, subestimam as vantagens comparativas chinesas no setor intensivo em trabalho, um resultado advindo da expressiva mãode-obra, ainda barata em relação ao mundo, presente no país. Ademais, a contabilização pela métrica do valor adicionado preservou os resultados encontrados pela estatística tradicional, isto é, setores que apresentavam vantagens comparativas pelas estatísticas tradicionais continuaram apresentando-a pelo valor adicionado.

Destaca-se que a taxa de crescimento de 2001 a 2010 aponta que a China elevou sua vantagem comparativa na tecnologia diferenciada e intensiva em escala e reduziu seu crescimento nas tecnologias intensivas em trabalho e recursos naturais. Considerando que o país iniciou suas atividades industriais como montador nas cadeias produtivas, ou seja, utilizando quantidade significativa de produtos intermediários importados fazendo com que a vantagem comparativa pelo valor adicionado seja menos intensa que pelas métricas tradicionais. Logo, as taxas de crescimento demostram um novo padrão de integração comercial construído pelo país a partir das políticas internas em prol de promover o catching up tecnológico. $O$ Brasil, por sua vez, apresentou queda na taxa de crescimento para todas as tecnologias avaliadas no que diz respeito ao setor industrial.

\section{Complexidade econômica: uma análise do espaço produto brasileiro e chinês entre 1990, 2000 e 2010}

Nesta seção, busca-se avaliar comparativamente o indicador de complexidade brasileiro e chinês. Para isto, define-se tal como propõe Hausmann et al (2013) 
"economias complexas" como aquelas que possuem vasta quantidade de conhecimento relevante e organizado para gerar um mix de produtos intensivos em conhecimento. A expansão da base de conhecimento, segundo os autores é construída pela interação dos indivíduos, redes de mercados e organizações. Assim, na perspectiva de cadeias globais de valor os países deveriam promover abertura econômica, aumentando suas interações e oportunidades de adquirirem e acumularem novos conhecimentos e criarem novas capacidades.

Metodologicamente, essa literatura passou a questionar como mensurar a complexidade econômica, isto é, como distinguir entre o que um país faz e o que ele sabe. Dessa forma, avalia-se que o montante de conhecimento incorporado em um país é expresso na sua diversidade produtiva, isto é, a quantidade de distintos produtos que é capaz de fazer. Além disso, produtos que exigem grandes volumes de conhecimento são viáveis apenas nos poucos lugares em que todos os requisitos estão disponíveis. Essa "onipresença" de um produto em relação aos países produtores é o que será medido pela ubiquidade.

Produtos com mais conhecimento incorporado serão menos ubíquos, isto é, estarão presentes em menor proporção em diversos lugares ${ }^{12}$. No entanto, a ubiquidade, ou seja, um produto estar presente em poucos países pode estar associado a raridade do produto e não ao fato de esse demandar muito conhecimento que o faça mais difícil de ser produzido. Logo, a diversidade corrige a ubiquidade e essa corrige aquela em uma perspectiva matematicamente interativamente a fim de produzir o índice de complexidade econômica (ICE).

Dessa forma, fazendo uso deste instrumento, analisa-se no Gráfico 3 o índice de complexidade para o Brasil e para à China no período de 2000 a 2011. Pode-se averiguar uma tendência de aumento do indicador chinês em contrapartida a uma queda do brasileiro, principalmente a partir de 2007. O indicador permite avaliar que

\footnotetext{
12 Uma analogia proposta pelo Atlas da complexidade é o uso de letras- R, A e C - para formar palavras - CAR ou ARC - de forma que as letras seriam o conhecimento e as palavras, os produtos. O número de jogadores (países) que podem fazer uma palavra indica sobre a variedade de letras que cada palavra exige. Isto é, palavras pequenas (produtos que exigem pouco conhecimento) tendem a ser comum e palavras longas, tendem a ser mais difíceis (muitas letras, muito conhecimento). A raridade de algumas letras, no entanto, faz com que alguns jogadores tenham palavras que poucos outros têm. Logo, além de conseguir colocar produtos diferentes esses precisam estar presentes em alguns outros países, para que não seja resultado da raridade, mas da disponibilidade um leque de conhecimento pelos países (capacidade em fazer produtos complexos). Isso explica, por sua vez, porque a diversidade é uma medida corretora da ubiquidade e vice-versa. (HAUSMANN et al, 2011, p. 20)
} 
as economias estiveram próximas em termos de complexidade desde o "boom" chinês, em 2003, até a crise financeira internacional, em 2008.

No mesmo sentido, pode-se notar o ranking das duas economias mensurado a partir do ICE. A economia brasileira era melhor posicionada que a chinesa no início dos anos 2000. No entanto, há um distanciamento das economias possivelmente relacionado as diferentes estratégias nacionais. O resultado desse processo pode ser visto à medida que em 2015 a China encontrava-se como 19º economia em termos de complexidade enquanto o Brasil ficou na $51^{\circ}$ posição.

Gráfico 3- Índice de complexidade (esquerda) e ranking (direita) do Brasil e da China

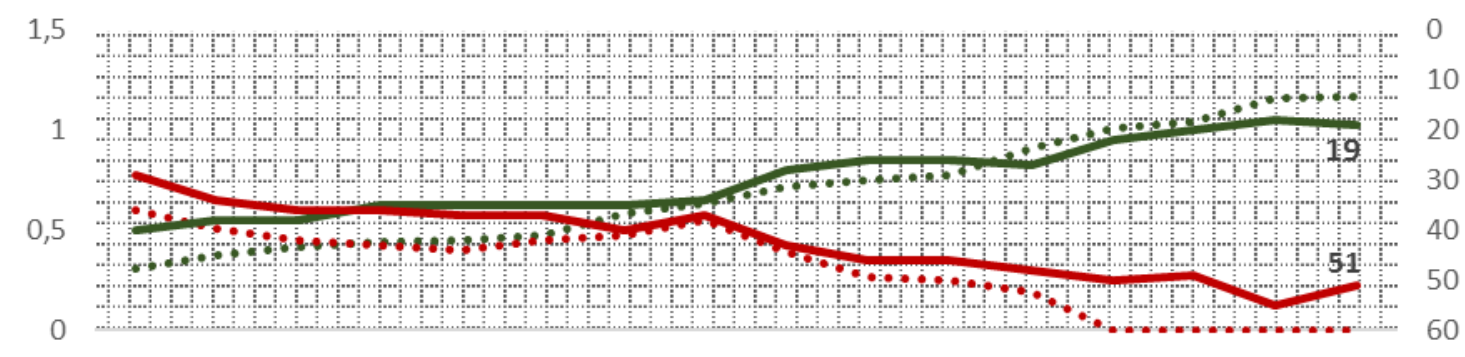

2000200120022003200420052006200720082009201020112012201320142015



Fonte: Elaboração própria a partir de dados do Observatório da Complexidade Econômica

Além disso, pode-se avaliar a complexidade pela ótica espacial, isto é, novas capacidades serão mais facilmente acumuladas pelos países se puderem ser combinadas com outras que já existentes, reduzindo a necessidade de coordenar o acúmulo de novos recursos simultaneamente. Com isso, os países diversificarão se movendo de produtos que já produzem para aqueles que requerem conhecimento tácito similar. Além disso, esses produtos são mais propensos de serem coexportados. Nesse sentido, a informação espacial passa a importar de forma que o espaço-produto afeta a habilidade dos países em se moverem para novos produtos. Assim, países que desejam ter alta complexidade econômica precisam desenvolver um espaço-produto altamente conectado.

Dessa forma, os países com baixos níveis de complexidade tendem a ter poucas oportunidades disponíveis já que os produtos criados tendem a ser "periféricos" no espaço produto. Já as economias complexas tendem a ter poucas novas oportunidades à medida que já ocuparam uma grande fração do espaço produto. Por outro lado, os países com nível intermediário de complexidade têm elevadas oportunidades. Entende-se, dessa forma, que o espaço-produto permite 
observar alterações no padrão de especialização dos países ao longo do tempo e, com isso, a evolução das possibilidades de expansão. De acordo com Dallaverde (2017) isto insere na complexidade uma perspectiva da evolução estrutural e especialização das economias.

Britto et al (2016) avaliaram a média do índice de complexidade do produto por setor tecnológico. Os autores encontram que há uma correlação entre o conteúdo tecnológico de cada indústria e o nível de complexidade da sua produção, isto é, para indústrias primárias o índice de complexidade do produto é $-0,711$, para as baseadas em recursos naturais, $-0,230$, para as de baixa tecnologia, 0,205 , as de média tecnologia, 0,714, as de alta tecnologia, 0,806 e outras manufaturas 0,120 . Dessa forma, os autores conseguiram associar as transformações na estrutura produtiva para indústrias de maior intensidade tecnológica como um processo de aumento da complexidade do país.

Com isso, apresenta-se na Figura 1 o espaço produto proposto por Hausmann et al. (2011) no "Atlas da Complexidade". Assim, pode-se analisar o índice de complexidade do produto (ICP) por categorias e a identificação desses no mapa, ou seja, se representam maiores ou menores possibilidades de ligações.

Figura 1- $O$ espaço produto

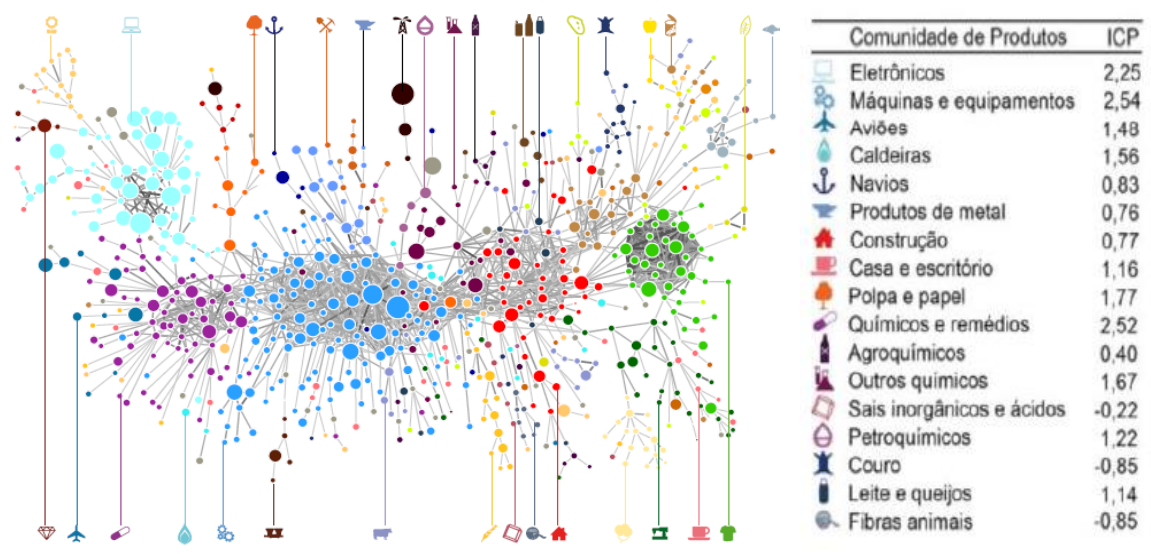

\begin{tabular}{|c|c|}
\hline Comunidade de Produtos & ICP \\
\hline F Carnes e ovos & 0,64 \\
\hline * Peixes & $-1,23$ \\
\hline 2 Agricultura tropical & $-1,95$ \\
\hline Cereais e obleos vegetais & $-0,34$ \\
\hline Algodâo, arroz, soja e outros & $-2,25$ \\
\hline Tabaco & $-1,46$ \\
\hline Frutas & $-0,58$ \\
\hline Agricultura diversa & $-0,79$ \\
\hline ? Não classificados & 0,93 \\
\hline I Tecidos & 0,18 \\
\hline Vestuário & $-0,43$ \\
\hline Comida processada & $-0,07$ \\
\hline Pedras preciosas & 0,02 \\
\hline In Carvằ & 0,21 \\
\hline Â Petróleo & $-2,08$ \\
\hline Mineraçăo & $-0,59$ \\
\hline If Bebidas e cigarros & 0,07 \\
\hline
\end{tabular}

Fonte: Hausmann et al. (2011)

Pela Figura 1, nota-se que produtos mais complexos estão localizados no centro da sua rede, oferecendo maiores possibilidades de diversificação. Já produtos com complexidade menor se encontram nas extremidades da rede, apresentando um menor número de ligações e maior distância para outros produtos $^{13}$.

${ }^{13}$ É importante destacar a noção de que em um espaço produto há "comunidades" altamente conectadas, isto é, produtos que usam uma quantidade semelhante de recursos e, portanto, 
Nesse sentido a diversificação tende a ocorrer até encontrar limites auto impostos pelas dotações de capacidades iniciais da economia. Além disso, o catching up será progressivamente mais difícil para os países complexos que precisam encontrar novos espaço em uma rede já altamente conectada (o aumento da base de conhecimento facilita a expansão para produtos em padrões próximos, mas dificulta novas descobertas). No entanto, esse mesmo processo pode promover lock-in na dinâmica inovativa dos países "atrasados", em que os investimentos são mais lucrativos em produtos já estabelecidos, dificultando a diversificação.

Ademais, é importante articular a discussão das transformações nas interações no espaço produto ao processo de internacionalização da produção. Esse arcabouço internacional possibilitou o aumento do comércio intra e intersetorial e elevou os esforços tecnológicos por parte dos países mais avançados em busca de garantirem o controle de ativos específicos nos processos produtivos de forma que 0 conhecimento não fosse uniformemente espraiado. Com isso, Britto et al (2016) avaliam que o espaço produto muda sua configuração de 1965 a 2005 tornando a rede mais alongada e fazendo com que o caminho para o desenvolvimento nacional tome a forma de $U$ aumentando a distância entre produtos simples e complexos, isto é, tornando mais difícil a coexportação de produtos.

Dessa forma, busca-se analisar a evolução do espaço produto chinês e brasileiro ao longo dos anos 1990, 2000 e 2010 para averiguar as transformações que se configuraram nas duas economias, que representa diferentes formas de acoplamento global. Destaca-se que, segundo Hausmann et al. (2011) além da heterogeneidade do espaço-produto, pode-se avaliar a conexão desses (ou seja, a densidade da rede), isto é, se mais conectados, há mais facilidade de adicionar recursos e expandir para novos produtos. Se conectados mais frouxamente é necessário maior acúmulo de recursos e investimento.

Nessa perspectiva, nota-se pela Figura 2 que em 1990 a China apresentava em seu espaço-produto uma rede de produtos com elevado índice de complexidade, como eletrônico, e produtos nos quais possui vantagens comparativas, como o têxtil. No entanto, a trajetória industrial chinesa nesse período era associada a uma 
"maquila", ou seja, a presença de produtos com maior complexidade se devia a cópia.

A economia brasileira, por sua vez, apresentava uma rede relativamente vasta de produtos do setor de máquinas e equipamentos e mais conectada se comparada a economia chinesa. Além disso, o país possuía diversos produtos do setor de químico e farmacêutico e produtos relacionados a materiais de construção e equipamentos. Assim, pode-se notar que se a construção de capacidades fosse dada, ceteris paribus, apenas pela intensidade tecnológica dos produtos que o país já produzia, a economia brasileira estaria bem posicionada em termos de complexidade.


Figura 2- Espaço-produto chinês

(esquerda) e brasileiro (direita) em 1990

Fonte: Elaboração própria a partir de dados do Observatório da Complexidade Econômica

No que diz respeito aos anos 2000, nota-se ao comparar a Figura 2 (anos 1990) e a Figura 3 (anos 2000) que o Brasil buscou construir novas competências e manteve seu espaço-produto diversificado conservando produtos com elevadas conexões como o de máquinas e equipamentos e construção. O país apresentava no seu mapa produtos relacionados ao setor aeronáutico, com elevado índice de complexidade do produto, e ao setor da soja.

A China, por sua vez, não apresentou mudanças radicais no seu espaço produto, tendo expandido o setor de construção. No entanto, é importante destacar que as exportações chinesas quadruplicaram enquanto as brasileiras dobraram. Isto é, o país asiático manteve seu espaço-produto relativamente diversificado mesmo ampliando significativamente seu volume de vendas. Dessa forma, percebe-se que esse movimento faz parte da estratégia do país de inserção internacional, 
expandindo sua participação nos fluxos


comerciais globais, viabilizando um

processo de learning by doing que, na perspectiva do aprendizado, é cumulativo.

Figura 3- Espaço-produto chinês (esquerda) e brasileiro (direita) em 2000

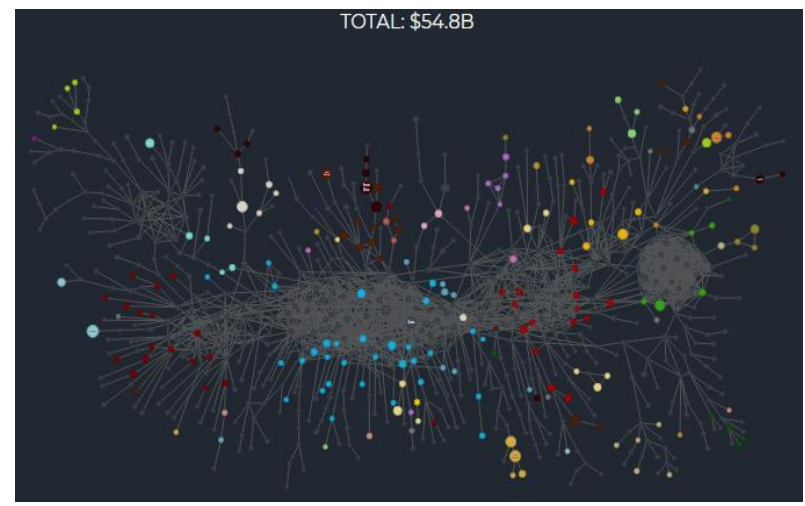

Fonte: Elaboração própria a partir de dados do Observatório da Complexidade Econômica

No caso chinês nota-se a construção de vantagens comparativas dinâmicas através do delineamento de estratégias de longo prazo concatenadas ao aumento dos gastos em P\&D como percentual do PIB, elevação das exportações de alta intensidade tecnológica, investimento em educação, entre outras variáveis conforme analisam Araújo, Brandão e Diegues (2018). Com isso, o país asiático manteve, em 2010, produtos em que possui vantagens comparativas estáticas, como os intensivos em trabalho, e avançou na ampliação das conexões de produtos com alta complexidade como eletrônicos, máquinas e equipamentos, químicos e farmacêuticos e relacionados a construção como pode ser visto na Figura 4. Entende-se que o país avançou na especialização tecnológica.

Por sua vez, o Brasil perdeu conexões no mesmo período, reduzindo a importância dos setores da aeronáutica, químico e farmacêutico sem a contrapartida do desenvolvimento de setores com alta complexidade, como o eletrônico. Ou seja, o país aprofundou sua especialização regressiva como pode ser visto na Figura 4. 
Figura 4- Espaço-produto chinês (esquerda)


e brasileiro (direita) em 2010

Fonte: Elaboração própria a partir de dados do Observatório da Complexidade Econômica

Ao avaliar a trajetória chinesa e brasileira, questiona-se, portanto, se o desenvolvimento a partir da inovação e transformação estrutural é apenas dado pela trajetória dependente da cesta de produtos inicialmente produzida ou se esse movimento está inserido em uma dinâmica de superação face às novas demandas internas e as diferentes organizações internacionais da produção. Afinal, a construção de novas capacidades aumentando o dinamismo dos produtos, as interconexões e expansão das possibilidades de desenvolvimento não representam um processo natural. Nessa perspectiva, se o desenvolvimento pode ser compreendido, nesta literatura, sob o princípio da transformação nas forças produtivas com objetivo de promover o adensamento da complexidade econômica, como destacou Dallaverde (2017), a China estaria promovendo um processo virtuoso comparado ao Brasil mesmo face às oportunidades e desafios oferecidos pelo cenário internacional.

Por fim, destaca-se Marcato (2018) ao avaliar que existe, para alguns países, uma associação - não expressa no sentido de causalidade - entre a participação nas cadeias globais de valor e o índice de complexidade econômica ${ }^{14}$ entre 1995 e 2011. No entanto, ainda que a validade da relação possa ser observada no caso chinês, não é observada no caso brasileiro, em que houve um aumentou da participação nas cadeias globais de valor e queda no índice de complexidade econômica. Assim, argumenta-se que esse o esforço de associação da autora é

\footnotetext{
14 Marcato (2018) reitera que as métricas partirem de cálculos diferentes, isto é, o indicador de complexidade usa dados brutos de comércio e os de participação nas cadeias globais usam dados de valor adicionado.
} 
consoante ao objetivo desse trabalho à medida que reforça a discussão de que a participação nas cadeias globais de valor permite novas oportunidades de upgrading, mas não é um processo passivo, ou seja, requer um arranjo articulado de políticas domésticas.

\section{Considerações finais}

Buscou-se ao longo deste trabalho compreender o processo de globalização e o espraiamento da estrutura produtiva ao redor do globo como provedor de riscos e oportunidades aos países atrasados no desenvolvimento industrial. Isto é, entendese que a globalização poderia ter sido aproveitada como uma janela de oportunidades através da condução de políticas internas que possibilitasse uma inserção virtuosa às cadeias globais e aumento da complexidade econômica. Para tal análise, o trabalho faz uso de dois países com trajetórias distintas no processo: Brasil e China.

No caso chinês, nota-se que além de estar mais inserido nas cadeias globais de valor, o país tem conduzido o processo em tecnologias mais dinâmicas configurando um distanciamento qualitativo no acoplamento global em relação a economia brasileira - haja vista a ampliação do distanciamento em relação a tecnologia diferenciada ao longo dos anos de 1995 a 2011. Além disso, notou-se pelo índice de complexidade que no período de 2000 a 2011 houve uma tendência de aumento do indicador chinês em contrapartida a uma queda do brasileiro.

No entanto, entende-se que os resultados encontrados através dos indicadores já eram esperados em vista das transformações observadas nas duas economias ao longo dos anos. Isto é, o processo de industrialização conduzido pelo estado chinês priorizando setores estratégicos e de reprimarização da pauta exportadora brasileira. Entretanto, destaca-se que o catching up será progressivamente mais difícil para a economia brasileira à medida que o aumento da complexidade dos produtos proporciona retornos para países já complexos - no sentido da coexportação - além dos fatores estruturais, como as transformações da indústria 4.0, já inseridas no planejamento chinês.

Defende-se, assim, que os condicionantes dos resultados díspares para as economias estão relacionados as políticas domésticas. No caso brasileiro, essas estiveram associadas ao arcabouço liberal nos anos 1990 e depois desarticuladas. Isto é, as políticas macroeconômica, tributária, industrial não representavam partes 
de um todo que vislumbrasse o longo prazo, culminando na desarticulação do tecido industrial nacional e na associação às cadeias de valor como um país fornecedor de produtos intensivos em recursos naturais. Em contrapartida, a China concatenava suas políticas domésticas e ponderava a adoção das medidas recomendadas pelo Consenso de Washington, isto é, o país enfatizava a defesa da indústria nacional e o avanço para elos mais nobres da produção, pautados na inovação.

Dessa forma, conclui-se que a globalização, por si, não representou um fenômeno nefasto ao desenvolvimento dos países atrasados. Na verdade, representa um conjunto de oportunidades, riscos e desafios às economias emergentes, que poderiam utilizá-la como instrumento para superar o path dependence. Para tal, os países deveriam articular domesticamente as políticas vislumbrando um horizonte de longo prazo em que a fronteira tecnológica e o paradigma produtivo seriam levados em consideração enquanto fatores móveis.

\section{REFERÊNCIAS}

AGLIETTA, M. e BAI, G. China's Development: Capitalism and empire. London \& Nova York: Routledge. 2013. Caps 3 e 4.

ARAÚJO, C. G; BRANDÃO, C. M; DIEGUES, A. C. A s transformações no modelo de desenvolvimento econômico chinês: de Deng Xiaoping ao período atual. Economia Ensaios, Uberlândia, 33(1): 1-40, Jul./Dez. 2018.

ARAÚJO, C. G.; DIEGUES, A. C. Uma análise do processo de catching up chinês e falling behind brasileiro na perspectiva da integração internacional às cadeias globais de valor de valor. Brazilian Journal of Development. Vol 5, no 1, 2019.

AREND, M. A industrialização do Brasil ante a nova divisão internacional do trabalho. Texto para Discussão, Instituto de Pesquisa Econômica Aplicada (IPEA), 2015.

BALASSA, B. Trade liberalization and revealed comparative advantage. Manchester School of Economics and Social Studies, v.33, n. 2, p. 99- 123, maio.1965.

BELLUZZO, L. G. A internacionalização recente do regime do capital. Campinas: CESIT/IE/UNICAMP - Carta Social e do Trabalho 27 - julho/setembro de 2014.

BERALDO, L. A China no século XXI: alguns apontamentos sobre sua inserção nas cadeias globais de valor e sobre a internacionalização de seus capitais. Encontro Nacional de Economia Política. Campinas, 2017.

BRESSER-PEREIRA, L. C.; MARCONI, N. Existe Doença Holandesa no Brasil? In: BRESSER-PEREIRA, L. C. (Org.). Doença holandesa e indústria (coletânea). Rio de Janeiro: Editora FGV, 2010. 
BRITTO, G., ROMERO, J., FREITAS, E., COELHO, C. The great divide: Economic complexity and development paths in Brazil and South Korea. Conference paper. ABEIN. 2016.

CARVALHO, V. R. S. A restrição externa e a perda de dinamismo da economia brasileira: investigando as relações entre estrutura produtiva e crescimento econômico. Encontro ANPEC, 2007.

CASSIOLATO, J. E; PODCAMENI, M. G. B. As políticas de ciência, tecnologia e inovação na China. In: China em transformação: Dimensões econômicas e geopolíticas do desenvolvimento. IPEA, 2015.

COEHN, W. M..; LEVINTHAL, D. A. Absorptive capacity: a new perspective on learning and innovation. Administrative science quarterly, 1990.

CUNHA, S. F.; XAVIER, C. L. Fluxos de investimento direto externo, competitividade e conteúdo tecnológico do comércio exterior da China no início do século XXI. Revista de Economia Política, vol. 30, no 3 (119), pp. 491-510, 2010.

DALLAVERDE, T. Estrutura produtiva e complexidade. Dissertação apresentada ao programa de Desenvolvimento Econômico da Universidade Federal do Paraná, 2017.

DIEGUES, A. C.; ROSSI, C. G. Além da desindustrialização: transformações no padrão de organização e acumulação da indústria em um cenário de 'Doença Brasileira'. Texto para discussão. Instituto de Economia da Unicamp. 2017.

EUROPEAN CHAMBER. China manufacturing 2025: Putting industrial policy ahead of market forces (2017). Disponível em:< http://docs.dpaq.de/12007-

european_chamber_cm2025-en.pdf>. Acesso em: 20 maio 2018

GEREFFI, G., STURGEON, T. e HUMPRHEY, J. The governance of global value chains. Review of international political economy, 12:1. 2005

HAUSMANN, R. et al. The Atlas of Economic Complexity: mapping Paths to Prosperity. Cambridge, MA: Harvard University, 2011. 368 p. 2013.

HERMIDA, C. C. Padrão de especialização comercial e crescimento econômico: uma análise sobre o Brasil no contexto da fragmentação da produção e das cadeias globais de valor. Tese de doutorado apresentada ao Programa de Pós-Graduação em Economia do Instituto de Economia da Universidade Federal de Uberlândia, 2016.

KOOPMAN, R.; WANG, Z.; WEI, S. Tracing value-added and double counting in gross exports. NBER WORKING PAPER SERIES, no 18579. Cambridge: [s.n.], 2012.

LALL, S. Globalização e desenvolvimento: perspectivas para as nações emergentes. Desenvolvimento em debate. 2002.

LI, L. China's manufacturing locus in 2025: With a comparison of "Made-in China 2025" and "Industry 4.0", 2018.

MARCATO, M. B. Trade integration in a vertically fragmented production structure: Theory, metrics, and effects. Tese de Doutorado apresentada ao Programa de Pós-Graduação em Ciências Econômicas, área de concentração: Teoria Econômica do Instituto de Economia da Universidade Estadual de Campinas, 2018. 
MASIERO, G.; COELHO, D. B. A política industrial chinesa como determinante da estratégia going global. Revista de Economia Política, v. 34, n. 1, 2014.

MEDEIROS, C. A. Padrões de investimento, mudança institucional e transformação estrutural na economia chinesa. In CGEE. Padrões de Desenvolvimento Econômico (1950-2008): América Latina, Ásia e Rússia - Volume 2. 2013.

MILARÉ, L.F.L. O processo de industrialização chinesa: uma visão sistêmica. 2011. 176 f. Dissertação (Mestrado em Economia) - Universidade Federal de São Carlos, Sorocaba, 2011.

MORCEIRO, P. et al. Conteúdo Importado na Produção Industrial e na Demanda Final do Brasil Recente: uma proposta de indicadores de importação e de conteúdo nacional/estrangeiro. In: Anais do XL Encontro Nacional de Economia ANPECAssociação Nacional dos Centros de Pós-graduação em Economia, 2014.

OECD. Structural Adjustment and Economic Performance. Paris: Organization for Economic Cooperation and Development. 1987.

ORTUSO, A. C. O Brasil e as cadeias globais de produção. Campinas: CESIT/IE/UNICAMP - Carta Social e do Trabalho 27 - julho/setembro de 2014.

PALMA, Gabriel. Latin America during the second half of the century: From the "age of extremes" to the age of "end-of-history" uniformity. 2004.

SARTI, F.; HIRATUKA, C. Indústria mundial: mudanças e tendências recentes. Campinas: Unicamp. IE, 2010. 34p. Texto para Discussão, n.186, 2010. SARTI, F.; HIRATUKA, C. Desempenho recente da indústria brasileira no contexto de mudanças estruturais domésticas e globais. Campinas: Unicamp. IE, 2017.

SARTI, F.; LAPLANE, M. F. O investimento direto estrangeiro e a internacionalização da economia brasileira nos anos 1990. Economia e Sociedade, v. 11, n. 1, p. 63-94, 2002.

TAGLIONI, D.; WINKLER, D. Making global value chain work for development. Economic Premise. Word Bank. Number 143. 2014. Disponível em:<

www.worldbank.org/economicpremise. >. Acesso em: 01 abr 2018.

OECD. Trade in Value Added. Disponível em:<

http://stats.oecd.org/index.aspx?r=59951\&erroCode=403\&lastaction=login_submit\#>.

Acesso em: 04 abr. 2018.

WANG, L. Comparative research on Germany "Industrie 4.0" and "Made in China 2025". 2016.

WILLIAMSON, J. Nossa agenda e o Consenso de Washington. In: WILLIAMSON, J.; KUCZINSKI, P. (org.) Depois do Consenso de Washington: retomando o crescimento e a reforma na América Latina. São Paulo. Saraiva, 2004.

\section{NOTAS DE AUTOR}

\section{CONTRIBUIÇÃO DE AUTORIA}

Caroline Giusti Araújo - Concepção. Coleta de dados, Análise de dados, Elaboração do manuscrito, revisão e aprovação da versão final do trabalho

Antônio Carlos Diegues - Concepção e elaboração do manuscrito. Participação ativa da discussão dos resultados; Revisão e aprovação da versão final do trabalho. 


\section{FINANCIAMENTO}

Bolsa de Mestrado CNPq durante o período 03-2017 a 02-2019, no Instituto de Economia da Unicamp.

Bolsa de Doutorado CNPq durante o período 03-2019 a 02-2023, no Departamento de Política Científica e Tecnológica do IGE Unicamp.

\section{CONSENTIMENTO DE USO DE IMAGEM}

Não se aplica.

\section{APROVAÇÃO DE COMITÊ DE ÉTICA EM PESQUISA}

Não se aplica.

\section{CONFLITO DE INTERESSES}

Não se aplica.

\section{LICENÇA DE USO}

Este artigo está licenciado sob a Licença Creative Commons CC-BY. Com essa licença você pode compartilhar, adaptar, criar para qualquer fim, desde que atribua a autoria da obra.

\section{HISTÓRICO}

Recebido em: 19-03-2020

Aprovado em: 05-11-2020 